\title{
ANALISIS PENGGANTIAN MATERIAL AGREGAT KLAS A DAN B MENJADI CTRB PAKET PENINGKATAN JALAN MUARA TEWEH - BENANGIN MENGGUNAKAN METODE AASTHO'93
}

\author{
MATERIAL REPLACEMENT ANALYSIS CLASS A AND B AGGREGATES BECOME A CTRB OF \\ ROAD IMPROVEMENT PACKAGE MUARA TEWEH - BENANGIN USING THE AASTHO'93 \\ METHOD
}

\author{
Nasib A. Sera \\ Aparatur Sipil Negara \\ Balai Pelaksanaan Jalan Nasional Palangka Raya \\ Direktorat Jenderal Bina Marga Kementerian Pekerjaan Umum dan Perumahan Rakyat \\ Korespondensi: asera310769@gmail.com
}

\begin{abstract}
ABSTRAK
Jalan merupakan salah satu prasarana yang akan mempercepat pertumbuhan dan pengembangan suatu daerah serta membuka hubungan sosial ekonomi, dan budaya antar daerah. Seiring dengan kemajuan infrastruktur maka pemerintah mengembangkan sarana transportasi yaitu berupa peningkatan jalan Muara Teweh Benangin. Di dalam undang-undang Republik Indonesia No.38 tahun 2004 tentang prasarana jalan bahwa jalan mempunyai peranan penting dalam mewujudkan perkembangan kehidupan bangsa. Peningkatan jalan Muara Teweh - Benangin menggunakan perencanaan tebal perkerasan lentur jalan dengan metode AASTHO 1993, direncanakan umur jalan untuk perkerasan lentur 20 tahun dan faktor pertumbuhan lalu lintas sebesar 6\%. Sumber data yang digunakan untuk merencanakan perkerasan lentur diperoleh dari Kementrian Pekerjaan Umum Direktorat Jendral Bina Marga - Balai Besar Pelaksana Nasional VII. Data yang berasal dari dokumentasi adalah data CBR tanah dasar dan lalu lintas rata - rata (LHR). Data - data tersebut merupakan dasar yang paling dibutuhkan dalam merencanakan perkerasan lentur dengan metode AASTHO 1993. Berdasarkan hasil perhitungan perencanaan tebal perkerasan lentur dengan metode AASTHO didapat perbandingan sebagai berikut: (a) total tebal lapisan permukaan HRS-Base/ATB $6 \mathrm{~cm}+\mathrm{HRS}$ WC $3 \mathrm{~cm}$, lapisan pondasi atas klas $A=15 \mathrm{~cm}$, dan lapisan pondasi bawah klas $B=20 \mathrm{~cm}$ dengan biaya sebesar $\mathrm{Rp}$ 35.742.463.681,- dengan waktu pelaksanaan selama 265 hari kalender. (b) total tebal lapisan permukaan HRS-Base/ATB $6 \mathrm{~cm}+$ HRS WC $3 \mathrm{~cm}$, lapisan pondasi CTRB $35 \mathrm{~cm}$, dengan biaya sebesar Rp. 34.278.182.220,- dengan waktu pelaksanaan selama 250 hari kalender, sehingga terjadi efisiensi biaya sebesar Rp. 1.464.281.462,- dengan selisih waktu selama 15 hari kalender.
\end{abstract}

Kata Kunci: AASTHO’93, CTRB, Klas A Klas B

\begin{abstract}
Roads are one of the infrastructures that will accelerate the growth and development of an area and open up socio-economic and cultural relations between regions. Along with the progress of infrastructure, the government has developed transportation facilities, namely the improvement of the Muara Teweh - Benangin
\end{abstract}


road. In the Law of the Republic of Indonesia No.38 of 2004 concerning road infrastructure, roads have an important role in realizing the development of the nation's life. The improvement of the Muara Teweh Benangin road used the flexible pavement thickness planning with the AASTHO 1993 method, the planned road life for flexible pavement was 20 years and the traffic growth factor was 6\%. Sources of data used to plan flexible pavements were obtained from the Ministry of Public Works, Directorate General of Highways National Executive Office VII. The data derived from the documentation is CBR data of subgrade and average traffic (LHR). These data are the basis most needed in planning a flexible pavement using the AASTHO method 1993. Based on the results of the calculation of the flexible pavement thickness planning using the AASTHO method, the following comparisons are obtained: (a) the total thickness of the surface layer HRSBase / ATB $6 \mathrm{~cm}+H R S W C 3 \mathrm{~cm}$, the upper foundation layer of class A = $15 \mathrm{~cm}$, and the lower foundation layer of class $B=20 \mathrm{~cm}$ at a cost of Rp. 35,742,463,681, with an implementation time of 265 calendar days. (b) total surface layer thickness of HRS-Base / ATB $6 \mathrm{~cm}+H R S W C 3 \mathrm{~cm}$, foundation layer CTRB $35 \mathrm{~cm}$, at a cost of Rp. 34,278,182,220, - with execution time of 250 calendar days, resulting in a cost efficiency of Rp. $1,464,281,462$, - with a difference of 15 calendar days.

Keywords: AASTHO'93, CTRB, Class A Class B

\section{PENDAHULUAN}

\section{Latar Belakang}

Dalam era pembangunan dewasa ini banyak infrastruktur yang dibangun untuk mendukung kegiatan manusia diantaranya gedung bertingkat, perkantoran, pasar dan segala sesuatu yang berhubungan dengan aktivitas manusia dalam menjalankan roda kehidupan sehari-hari. Agar jalan dapat memberikan pelayanan sesuai yang diharapkan, maka jaminannya adalah selalu diusahakan adanya pemeliharaan dan peningkatan jalan tersebut. Dengan kemampuan daya tampung jalan yang terbatas dan bertambahnya jumlah lalu lintas kendaraan maka akan mengakibatkan kemacetan lalu lintas dan selanjutnya menimbulkan kerusakan jalan.

Kabupaten Barito Utara adalah salah satu kabupaten di provinsi Kalimantan Tengah. Ibu kota kabupaten ini terletak di Muara Teweh. Kabupaten ini memiliki luas wilayah $8.300 \mathrm{~km}^{2}$ dan berpenduduk sebanyak 123.781 jiwa (hasil Sensus Penduduk Indonesia 2012) terbagi menjadi 9 wilayah Kecamatan, 10 Kelurahan dan 93 Desa. Laju pertumbuhan ekonomi Kabupaten Barito Utara tahun 2012 sebesar 6,52 \% untuk tahun 2013 sebesar 7,13\%. (Data BPS, Tahun 2014).

Jalan darat merupakan salah satu transportasi yang sangat diperlukan oleh masyarakat kabupaten Barito Utara untuk pengembangan potensi ekonomi daerah. Ruas jalan Muara Teweh Benagin adalah jalan nasional poros tengah lintas Kalimantan dari provinsi Kalimantan Barat, Kalimantan Tengah ke provinsi Kalimantan Timur. Kondisi jalan ruas Muara Teweh - Benagin masih berupa pondasi aggregat klas B dan apabila hujan jalan menjadi licin dan sulit untuk dilewati. Kondisi pada ruas jalan ini mengalami kerusakan yang cukup serius dibeberapa lokasi sehingga mengurangi kelancaran lalu lintas kendaraan, sering terjadi kecelakaan, dan mengurangi kenyamanan pengguna jalan sehingga perlu ada penanganan untuk mengatasinya. Salah satu upaya untuk memperbaiki kerusakan jalan dengan pengembangan teknologi recycling terhadap perkerasan jalan yang rusak. Cement Treated Recycling Base-CTRB adalah merupakan teknologi stabilisasi pondasi jalan dengan sistem daur ulang material perkerasan jalan dengan bahan additive semen. Material yang didaur ulang dengan semen tersebut dimanfaatkan dari material yang sudah ada dari perkerasan lama dan digunakan sebagai lapis pondasi atas (Cement Treated Recycling Base-CTRB).

Keunggulan lainnya dari sisi pertimbangan bahan bakar. Dengan tidak membutuhkan banyak material baru sehingga relatif tidak banyak mengeluarkan biaya pengangkutan dan juga proses pelaksanaan pekerjaan bisa lebih cepat. Dari Latar belakang maka penelitian ini adalah melakukan Rekayasa Nilai Penggantian

Material Agregat A dan Agregat B menjadi Cement Treated Recycling Base (CTRB) pada ruas jalan Muara Teweh - Benangin 2 yang mendesak untuk dilakukan. 


\section{Rumusan Masalah}

1. Berapa tebal perkerasan dengan jenis perkerasan lentur lapis pondasi atas Klas A dan lapis pondasi bawah Klas B?

2. Berapa tebal perkerasan dengan jenis perkerasan lentur Cement Treated Recycling Base-CTRB)?

3. Bagaimana mendapatkan nilai efisiensi biaya dan waktu antara lapis pondasi atas Klas A dan lapis pondasi bawah Klas B dengan lapis pondasi Cement Treated Recycling Base-(TRB)?

\section{Tujuan Penelitian}

1. Menentukan tebal perkerasan dengan jenis perkerasan lentur lapis pondasi atas Klas A dan lapis pondasi bawah Klas B

2. Menentukan tebal perkerasan dengan jenis perkerasan lentur Cement Treated Recycling Base-CTRB)

3. Mendapatkan nilai efisiensi biaya dan waktu antara lapis pondasi atas Klas A dan lapis pondasi bawah Klas B dengan lapis pondasi Cement Treated Recycling BaseCTRB)

\section{Batasan Masalah}

Dalam penulisan ilmiah ini hanya membatasi pada perhitungan biaya dan waktu. Masalahmasalah yang akan dibahas dengan memperhatikan begitu banyak metode yang digunakan dalam perencanaan tebal perkerasan jalan, serta dalam penulisan tesis ini, membatasi masalah pada perencanaan jalan menggunakan sistem perkerasan lentur dengan metode AASHTO 1993. Harga bahan dianggap stabil meskipun ada kenaikan tetapi secara bertahap, dan sumber data harga bahan dan upah serta waktu mengacu pada kontrak jalan Muara Teweh - Benangin 2 yang sudah dilaksanakan Tahun Anggaran 2014.

\section{Manfaat Penelitian}

Memberi gambaran yang jelas kepada:

1. Pemerintah Provinsi Kalimantan Tengah dan khususnya Dinas Pekerjaan Umum Provinsi Kalimantan Tengah.

2. Dunia Pendidikan, sebagai wahana perluasan ilmu pengetahuan dibidang perencanaan jalan yang terkait dengan Cement Treated Recycling Base-CTRB.

\section{TINJAUAN PUSTAKA}

\section{Penelitian Terdahulu}

- Anastasia H. Muda (2009). Tinjauan Kuat Tekan Bebas dan Drying Shrinkage Cement Treated Recycling Base (CTRB) pada Rehabilitasi Jalan Boyolali-Kartasura

- Karsikun,dkk (2008). Pada akhir tahun 2008, diruas jalan Boyolali-Kartosuro dilaksanakan rehabilitasi jalan sepanjang $6.95 \mathrm{~km}$ dengan metode Cement Treated Recycling Base (CTRB).

- PUSLITBANG Jalan Jembatan (2002). Penelitian Daur ulang lapis perkerasan beton aspal dengan bahan tambah semen oleh PUSLITBANG Jalan Jembatan tahun 2002.

- PUSLITBANG Jalan Jembatan (2003). Penelitian yang sama dilanjutkan oleh PUSLITBANG Jalan Jembatan pada tahun 2003.

- PUSLITBANG Jalan Jembatan (2006). Penelitian dilanjutkan oleh PUSLITBANG Jalan Jembatan pada tahun 2006.

\section{Dasar Teori}

1. Perkerasan jalan adalah suatu konstruksi yang dibangun di atas tanah dasar dengan tujuan untuk dapat menahan beban lalu lintas kendaraan, serta mampu bertahan terhadap perubahan cuaca.

2. Perkerasan lentur (flexible pavement) adalah merupakan perkerasan yang menggunakan aspal sebagai bahan pengikat sebagai lapis permukaan dan dibawahnya ada lapisan pondasi berbutir sehingga mempunyai sifat lentur (flexible) yang cukup besar baik pada lapisan permukaan sebagai lapisan aus dan lapisan berbutir sebagai pondasi yang ada di bawahnya. Penyebaran Gaya berdasarkan teori pada pembebanan tanah, dimana beban kendaraan dilimpahkan ke lapis perkerasan jalan melalui bidang kontak roda yang terbagi secara merata. Dari beban yang diterima oleh lapisan permukaan kemudian disebarkan ke lapisan tanah dasar, beban tersebut kemudian didistribusikan ke fondasi jalan, bila daya 
dukung tanah tidak mampu menerima muatan beban maka jalan akan rusak.

3. Cement Treated Recycling Base-CTRB adalah merupakan teknologi stabilisasi pondasi jalan dengan sistem daur ulang material perkerasan jalan dengan bahan additive semen. Material yang didaur ulang dengan semen tersebut dimanfaatkan dari material yang sudah ada dari perkerasan lama dan digunakan sebagai lapis pondasi atas.

4. Jenis dan Lapisan Perkerasan Lentur. Unsurunsur kostruksi jalan pada perkerasan lentur umumnya terdiri dari 4 (empat) lapisan yang mempunyai fungsi sendiri-sendiri yang terdiri dari beberapa lapisan sebagai berikut yaitu:

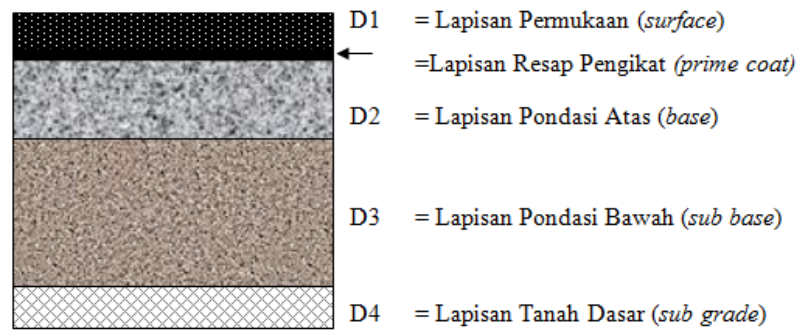

Gambar 1. Lapisan Perkerasan Lentur

- Lapisan permukaan (surface course) Agar dapat memenuhi fungsi sebagai lapisan kedap air, sebagai perkerasan menahan beban, sebagai lapis aus dan meneruskan beban, maka pada umumnya lapisan permukaan dibuat dengan menggunakan bahan pengikat aspal, sehingga menghasilkan lapisan kedap air dengan stabilitas tinggi dan daya tanah yang lama. Material yang digunakan untuk lapisan pondasi atas adalah material yang cukup kuat dan awet sehingga mampu menahan beban roda. Untuk lapisan pondasi atas tanpa bahan pengikat umumnya menggunakan material dengan CBR $>50 \%$ dan plastisitas indeks (IP) $<4 \%$. Terdapat bermacam-macam batuan alam yang dapat digunakan sebagai bahan lapisan pondasi atas antara lain: batu pecah, pasir alam, kerikil pecah, dan stabilitas tanah dengan semen atau kapur.

a) Sebagai lapisan kedap air, untuk melindungi jalan dari kerusakan akibat cuaca, sehingga air hujan yang jatuh diatasnya tidak meresap ke dalam lapisan di bawahnya yang melemahkan lapisan lapisan di bawahnya. b) Sebagai perkerasan yang mempunyai stabilitas yang tinggi untuk menahan beban roda dimana lapisan ini mampu untuk menahan beban roda kendaraan.

c) Sebagai lapisan aus atau selimut (wearing course) yaitu lapisan yang langsung menerima gesekan akibat rem kendaraan dengan tekanan roda, serta pengaruh cuaca dan iklim.

d) Sebagai lapisan untuk menyebarkan beban roda kendaraan ke lapisan di bawahnya sehingga dapat dipikul oleh lapisan yang mempunyai daya dukung lebih kecil.

- Lapisan pondasi atas (base course) adalah lapisan perkerasan yang terletak diantara lapisan permukaan dan lapisan pondasi bawah (sub base course).

- Lapisan pondasi bawah (sub base course) lapisan perkerasan yang terletak antara lapisan pondasi atas dan lapisan tanah dasar, dengan CBR $>20 \%$ dan plastisitas indeks (IP $<10 \%$ ).

- Lapisan tanah dasar (sub grade) merupakan lapisan tanah yang berada di bawah lapisan pondasi atau tanah timbunan dan sebagai lapisan paling bawah dari susunan lapis perkerasan.

5. Tahap - Tahap Perencanaan Tebal Perkerasan Lentur dengan Metode AASHTO yang dipakai untuk perencanaan perkerasan lentur dalam penelitian ini adalah metode AASHTO '93, yang ada dalam buku AASHTO Guide Design of Pavement Structures, 1993. (Soetoyo, 2010).

- Modulus Resilient $\left(\mathrm{M}_{\mathrm{R}}\right)$ pada AASHTO 1993 (diperoleh dari pemeriksaan AASHTO T274) disebutkan bahwa variabel tanah dasar yang dijadikan perhitungan tebal perkerasan adalah modulus resilent $\left(\mathrm{M}_{\mathrm{R}}\right)$ untuk perkerasan lentur.

- Lalu Lintas Harian Rata - Rata (LHR) adalah lintas harian rata - rata lalu lintas kendaraan bermotor roda empat atau lebih yang dicatat selama 24 jam penuh setiap jam dan juga dicatat pada waktu jam sibuk sehari untuk kedua jurusan.

- Faktor Pertumbuhan Lalu Lintas (i) faktor yang mempengaruhi pertumbuhan lalu lintas adalah: perkembangan daerah, pertambahan kesejahteraan masyarakat, naiknya kemampuan 
daya beli kendaraan bermotor. Faktor pertumbuhan lalu lintas tersebut dinyatakan dalam persen / tahun.

- Batasan Waktu menentukan batasan waktu meliputi pemilihan lamanya umur rencana dan umur kinerja jalan (performance period) atau menggunakan konstruksi bertahap atau tidak.

- Faktor Lingkungan dalam hal ini faktor temperatur dan kadar air mempunyai peran yang sangat penting. Perubahan kadar air pada tanah kembang susut akan berdampak besar terhadap nilai indeks pelayanan $(\Delta \mathrm{PSI})$.

- Reliabilitas (keandalan atau tingkat keyakinan) dalam perencanaan perkerasan, untuk mencapai umur pelayanan yang tepat. Artinya apabila angka keyakinan penuh, yaitu reliabilitas $\mathrm{R}=$ $100 \%$, berarti besar faktor keamanan yang dipertimbangkan, sehingga hasil perencanaan sangat aman, namun dengan konsekuensi biaya tinggi.

- Penentuan Angka Ekivalen Beban Sumbu Kendaraan $\left(\mathrm{E}_{\mathrm{i}}\right)$ semua beban kendaraan dengan beban sumbu berbeda diekivalenkan ke beban sumbu standard sebesar 18 kip dengan menggunakan angka ekivalen beban sumbu kendaraan (Ei).

- Penentuan Koefisien Distribusi Pada Lajur Rencana $\left(D_{L}\right)$ koefisien distribusi lajur dalam AAHSTO telah disesuaikan dengan jumlah lajur rencana di setiap arah. Penentuan Koefisien Distribusi Arah $\left(\mathrm{D}_{\mathrm{D}}\right)$ untuk koefisien distribusi arah biasanya diambil $\mathrm{D}_{\mathrm{D}}=50 \%$ tiap arah karena untuk menyeimbangkan volume lalu lintas yang dapat ditampung setiap arah.

- Lintas Ekivalen Kumulatif Selama Umur Rencana (W18) W18 adalah jumlah lintas ekivalen sumbu tunggal seberat 18 Kip $(8,1647$ ton) pada lajur rencana selama umur rencana atau sesuai dengan umur kinerja jalan tersebut.

- Kondisi Lingkungan merupakan Faktor penyebab perubahan kadar air pada tanah berbutir halus yang mengakibatkan tanah tersebut mengalami pengembangan (swelling) yang mengakibatkan kondisi daya dukung tanah dasar menurun.

- Penentuan Kriteria Kinerja Jalan Raya dinyatakan dalam nilai indeks permukaan (PSI).
Indeks permukaan adalah suatu angka yang menyatakan tingkat kerataan atau kehalusan serta kekokohan permukaan jalan yang berkaitan dengan kemampuan tingkat pelayanan lalu lintas kendaraan yang lewat jalan tersebut.

- Menentukan Faktor Koefisien Drainase. Dalam menentukan koefisien drainase mulai dari drainase kondisi baik sekali, baik, cukup dan buruk serta buruk sekali dengan nilai $\mathrm{m}_{2}, \mathrm{~m}_{3}$. Kondisi drainase yang direncanakan adalah kondisi baik dengan tingkat kelembapan di Indonesia relatif tinggi $>20 \%$.

- Menentukan Indeks tebal perkerasan (ITP) adalah suatu angka yang berhubungan dengan penentuan tebal perkerasan tiap lapis atau total tebal perkerasan. SN atau ITP dapat dicari dengan menggunakan nomogram G-6 dan rumus dasar AAHSTO'93 (2.12).

\section{METODE PENELITIAN}

\section{Rancangan Penelitian}

Hasil dari penelitian mengenai analisis biaya yang ekonomis dengan penggunaan perkerasan lentur dengan metode AASTHO 1993 pada struktur jalan perkerasan lentur agregat klas A dan Klas B dengan CTRB (Cement Treated Recycling Base) ditinjau dari umur rencananya 20 tahun pada pembangunan Jalan Muara Teweh - Benangin 2.

\section{Instrument Penelitian}

Instrumen dalam penelitian ini adalah menentukan hasil perencanaan jalan dengan perkerasan lentur agregat klas A dan Klas B dengan CTRB (Cement Treated Recycling Base) metode AASTHO 1993 dengan LASTON (Asphalt Treated Base-ATB) sebagai lapis permukaan, besarnya nilai CBR tanah dasar (sub grade) ditetapkan $90 \%$ dari CBR lapangan.

\section{Metode Pengumpulan Data}

Metode tersebut adalah merupakan uraian prosedur pengumpulan data baik dengan cara memperolehnya melalui pustaka maupun data lapangan yang akan digunakan dalam rangka untuk menjawab permasalahan penelitian atau untuk 
membuktikan dan merealisasikan tujuan serta manfaat penelitian

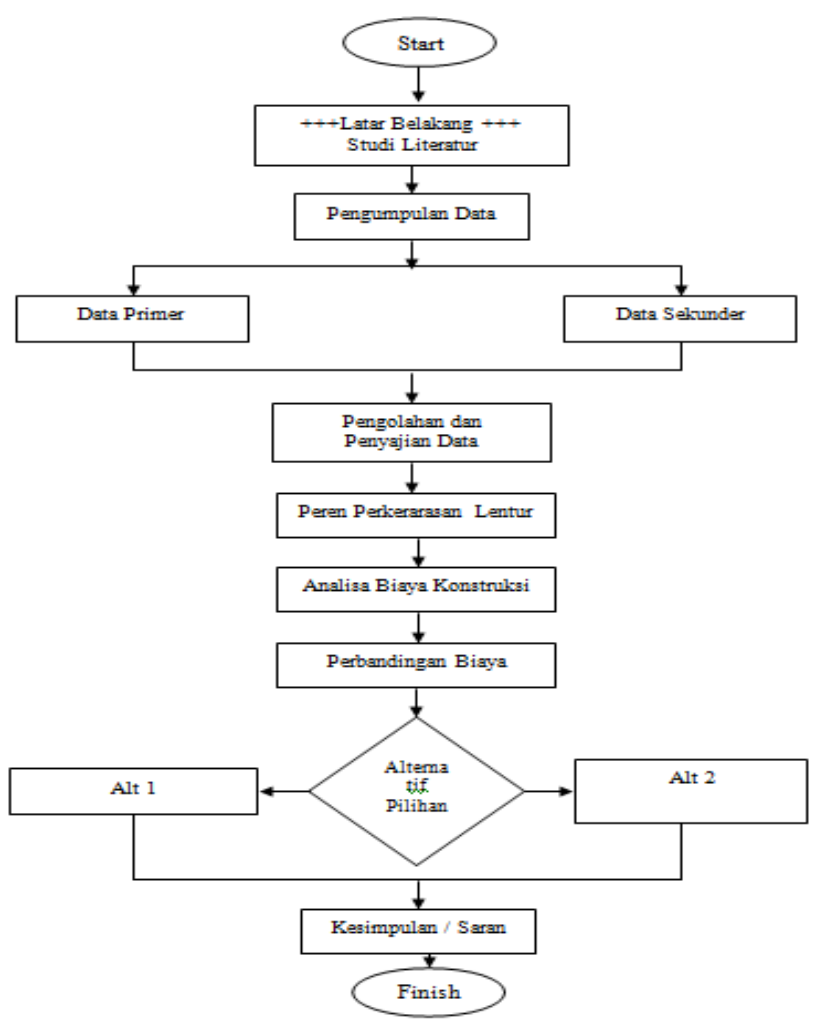

Gambar 2. Bagan Alir Penelitian

\section{Pengolahan Data}

Pengolahan data merupakan proses perhitungan lalu lintas kendaraan secara komulatif yang telah dikumpulkan dengan menggunakan rumusan yang telah ditentukan sehingga data tersebut akan lebih mudah dianalisis. Penentuan jumlah lalu lintas dan jenis kendaraan rata - rata per hari berdasarkan jumlah as dan berat kendaraan, tebal perkerasan, dan mengkorelasi nilai $\mathrm{CBR}$ ke harga $\mathrm{M}_{\mathrm{R}}$ (Modulus resilient).

\section{Analisis data}

Setelah semua data yang dibutuhkan terkumpul dan diolah maka langkah selanjutnya adalah melakukan analisis data tersebut dengan cara memasukkan ke dalam rumus yang relevan untuk mendapat hasil perencanaan yang baik. Data - data yang berhubungan dengan perkerasan lentur jalan tersebut dianalisa dengan metode AASHTO 1993.

\section{Umur Rencana Perkerasan Jalan}

Umur rencana perkerasan jalan adalah jumlah waktu dalam tahun yang dihitung sejak jalan tersebut dibuka untuk lalu lintas kendaraan sampai diperlukan suatu perbaikan berat atau dianggap perlu untuk diberi lapisan baru. Umur rencana untuk perkerasan lentur jalan baru (new road flexible pavement) umumnya diambil 20 tahun dan untuk peningkatan jalan (road betterment) adalah 20 tahun.

\section{Hasil Analisa Data}

Hasil analisis data didapatkan setelah semua yang dibutuhkan sudah terkumpul dan diolah, langkah selanjutnya adalah menganalisis data tersebut dengan cara dimasukkan ke dalam masing masing rumus yang relevan untuk mendapatkan hasil perencanaan.

\section{ANALISA DAN PEMBAHASAN}

Perhitungan kedua alternatif dengan umur rencana jalan 20 tahun.

Dari perhitungan didesain alternatif $1: \mathrm{AC}=3,5$ " (setebal $9 \mathrm{~cm}$ ); Agg Klas A = 6" (setebal $15 \mathrm{~cm}$ ); Agg Klas B = 8" (setebal $20 \mathrm{~cm}$ )

Dari perhitungan didesain alternatif $2: \mathrm{AC}=3,5$ " $(9 \mathrm{~cm}) ; \mathrm{CTRB}=14 ”(35 \mathrm{~cm})$.

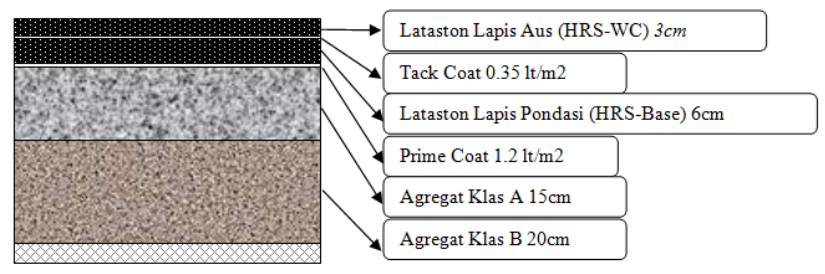

Gambar 3. Desain alternatif 1

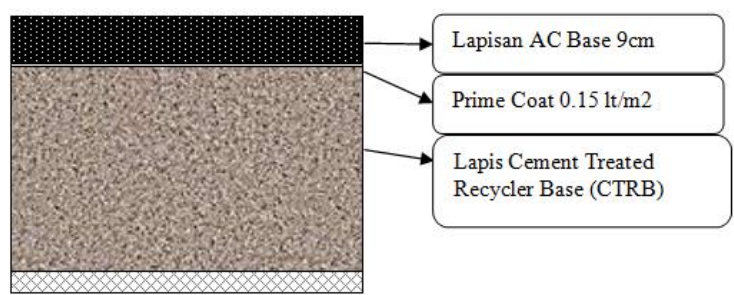

Gambar 4. Desain alternatif 2 


\section{Penetapan Biaya Pelaksanaan}

Biaya pekerjaan jalan pada Peningkatan Jalan Muara Teweh - Benangin 2, sepanjang $6.00 \mathrm{~km}$ dengan lebar 6,00 $\mathrm{m}$, dengan pekerjaan utama dan bangunan perlengkapan jalan dengan rincian Biaya Pelaksanaan Pekerjaan CTRB yang dikontrakkan sebagai berikut :

1. Biaya Kontraktual Asal, Konstruksi dengan lebar existing $6 \mathrm{~m}$ (dengan konstruksi semula agregat base klas B) dengan panjang rencana $6.00 \mathrm{~km}$, dilebarkan menjadi $6,50 \mathrm{~m}$ dengan pondasi Cement Treated Recycler Base (CTRB), dengan tebal $30 \mathrm{~cm}$ panjang $6.00 \mathrm{~km}$, dengan tebal HRS-Base $4 \mathrm{~cm}$, HRS-WC $3 \mathrm{~cm}$ maka besarnya volume pekerjaan dengan konstruksi utama, dengan bangunan pelengkap (bahu jalan, saluran drainase) dan perlengkapan jalan (marka jalan) biaya kontrak keseluruhan termasuk PPN adalah sebesar Rp. 31.475.000.000,00. dan jadual waktu pelaksanaan (dalam perencanaan) berupa kurva S sebesar 240 hari kalender.

2. Biaya Pelaksanaan Pekerjaan CTRB hasil perencanaan. Jika lebar existing $6 \mathrm{~m}$ (dengan konstruksi semula agregat base klas B) dan panjang penanganan $6.00 \mathrm{~km}$, dilebarkan menjadi $6,50 \mathrm{~m}$ dimana pondasi menggunakan Cement Treated Recycler Base (CTRB), dengan tebal $35 \mathrm{~cm}$ panjang $6.00 \mathrm{~km}$, dengan tebal HRS-Base $6 \mathrm{~cm}$, HRS-WC $3 \mathrm{~cm}$ maka besarnya volume pekerjaan dan biaya keseluruhan termasuk Pajak Pertambahan Nilai (PPN) adalah sebesar Rp. 33.617.206.995,50. dan jadual waktu pelaksanaan (dalam perencanaan) berupa kurva S sebesar 250 hari kalender.

3. Biaya Pelaksanaan Pekerjaan klas A dan klas B hasil perencanaan, konstruksi dengan lebar existing $6 \mathrm{~m}$ (dengan konstruksi semula agregat base klas B) dan panjang existing $6.00 \mathrm{~km}$, dilebarkan menjadi $6,50 \mathrm{~m}$ Klas A dan Klas B, dengan tebal masing-masing $15 \mathrm{~cm}$ dan $20 \mathrm{~cm}$ panjang $6.00 \mathrm{~km}$, dengan tebal HRS-Base $6 \mathrm{~cm}$, HRS-WC $3 \mathrm{~cm}$ maka besarnya volume pekerjaan dengan konstruksi utama, dengan bangunan pelengkap (bahu jalan, saluran drainase) dan perlengkapan jalan (marka jalan) biaya keseluruhan termasuk PPN adalah sebesar Rp. 35.081.488.457,00 dan jadual waktu pelaksanaan (dalam perencanaan) berupa kurva S sebesar 265 hari kalender.

\section{PENUTUP}

\section{Kesimpulan}

Berdasarkan analisis data dan pembahasan, serta tujuan penelitian, dapat disimpulkan bahwa:

1. Tebal perkerasan untuk lapis pondasi atas klas A dan klas B masing-masing $15 \mathrm{~cm}$ dan $20 \mathrm{~cm}$ dengan lapisan permukaan HRS-Base/ATB 6 $\mathrm{cm}$ dan HRS WC $3 \mathrm{~cm}$. Sedangkan untuk besarnya biaya sejumlah Rp 35.742.463.681,dan lama waktu pengerjaan 265 hari.

2. Tebal perkerasan untuk lapis pondasi CTRB adalah sebesar $35 \mathrm{~cm}$ dengan lapisan permukaan HRS-Base/ATB $6 \mathrm{~cm}$ dan HRS WC $3 \mathrm{~cm}$. Sedangkan untuk besarnya biaya sejumlah Rp 34.278.182.220,- dan lama waktu pengerjaan 250 hari.

3. Berdasarkan hasil perhitungan, biaya yang paling minimum adalah pada penggunaan material pondasi jenis CTRB dengan selisih biaya antara kedua alternatif adalah sebesar Rp 1.464.281.462.00

\section{Saran}

Saran adalah sebagai berikut:

1. Perkerasan jalan sebaiknya tanah dasar perlu dilakukan stabilisasi baik secara kimia (dengan semen, kapur) ataupun secara mekanis untuk memperkecil angka plastisitas agar tidak terjadi kembang susut pada tanah dasar yang dapat mengakibatkan perkerasan rusak.

2. Berdasarkan data yang diperoleh dan dari hasil perhitungan pada ruas jalan Muara Teweh - Benangin 2 Kabupaten Barito Utara agar dilakukan perawatan secara berkala sehingga jalan dapat berfungsi sesuai dengan umur yang telah direncanakan mengingat dana yang diperlukan untuk pembangunan jalan ini memakan dana yang cukup besar.

3. Diharapkan di masa yang akan datang penelitian ini dapat digunakan untuk sumber penelitian lebih lanjut berdasarkan faktor lainnya seperti perhitungan material atau desain perencanaan jalan di lokasi yang berbeda. 


\section{DAFTAR PUSTAKA}

AASHTO. (1993). Guide For Design Of Pavement Structures. Washington

Anastasia H. Muda, (2009). Penelitian tersebut berjudul: Tinjauan Kuat Tekan Bebas dan Drying Shrinkage Cement Treated Recycling Base (CTRB) pada Rehabilitasi Jalan Boyolali-Kartasura. 2009.

Badan Pusat Statistik Kabupaten Barito Utara, (2015), Barito Utara Dalam Angka 2015.

Koestalam, P., Sutoyo. (2010), Perencanaan Tebal Perkerasan Jalan Jenis Lentur dan Jenis Kaku (sesuai AASTHO, 1986 \& 1993). PT. Mediatama Saptakarya, Jakarta

Karsikun, dkk., (2008), Di ruas jalan BoyolaliKartosuro dilaksanakan rehabilitasi jalan sepanjang $6.95 \mathrm{~km}$ dengan teknologi recycling in situ metode Cement Treated Recycling Base (CTRB).

PUSLITBANG Jalan Jembatan, (2002), Penelitian Daur Ulang Lapis Perkerasan Beton Aspal dengan Bahan Tambahan Semen, Bandung

PUSLITBANG Jalan Jembatan, (2003), Lanjutan Penelitian Daur Ulang Lapis Perkerasan Beton Aspal dengan Bahan Tambahan Semen, Bandung.

PUSLITBANG Jalan Jembatan, (2006), Lanjutan Penelitian Daur Ulang Lapis Perkerasan Beton Aspal dengan Bahan Tambahan Semen, Bandung.

Sukirman, S. (1999), Perkerasan Lentur Jalan Raya. Nova, Bandung

Taha, dkk., (2002), Penelitian recycling lapis perkerasan lama dengan memanfaatkan Reclaimed Asphalt Pavement (RAP) berupa agregat alam yang distabilisasi Cement By-pass Dust sebagai lapisan perkerasan jalan. 